\title{
A APRENDIZAGEM-TRABALHO E AS TECNOLOGIAS DE SAÚDE NA ESTRATÉGIA SAÚDE DA FAMÍLIA
}

\author{
Renan Vasconcelos Pessanha ${ }^{1}$, Fátima Teresinha Scarparo Cunha²
}

\begin{abstract}
${ }^{1}$ Acadêmico do Curso de Graduação em Enfermagem da Escola de Enfermagem Alfredo Pinto (EEAP) da Universidade Federal do Estado do Rio de Janeiro (UNIRIO). Rio de Janeiro, Brasil. E-mail: renanpessanha@yahoo.com.br

${ }^{2}$ Doutora em Saúde Coletiva. Professor Adjunto do Departamento de Enfermagem de Saúde Pública da EEAP/UNIRIO. Rio de Janeiro, Brasil. E-mail: fatima.scarparo@gmail.com
\end{abstract}

RESUMO: Formação e capacitação de trabalhadores para o Sistema Único de Saúde são questões essenciais experimentadas pela Estratégia Saúde da Família. A Educação Permanente surge como proposta fundamentada na concepção de aprendizagem-trabalho, que por meio da reflexão crítica, desperta o profissional sobre sua realidade e processo de trabalho. O artigo tem como objetivo analisar o processo de aprendizagem-trabalho na Estratégia Saúde da Família no Complexo do Alemão, Rio de Janeiro-RJ, com base nas tecnologias de saúde. Estudo descritivo com abordagem qualitativa, por meio do método de análise de conteúdo. Realizou-se observação sistemática e entrevistas semi-estruturadas com médicos, enfermeiros e odontólogos, entre dezembro de 2007 e fevereiro de 2008. Os resultados mostram que os profissionais expressam conhecimentos apreendidos nas experiências cotidianas do trabalho e em atividades de educação permanente, constituindo um processo pedagógico de ensino-aprendizagem das equipes multiprofissionais, porém, pouco utilizado em ações de educação pelos gestores do Sistema Único de Saúde.

DESCRITORES: Programa saúde da família. Educação em saúde. Aprendizagem.

\section{ON-THE-JOB LEARNING AND HEALTH CARE TECHNOLOGIES IN THE FAMILY HEALTH STRATEGY}

\begin{abstract}
The formal education and professional training of workers in the Brazilian Federal Health Care System (Sistema Único de Saúde) are key issues experienced by the Family Health Strategy. Permanent Education has emerged as a proposal founded upon the on-the-job learning conception, which awakens the professional about his/her reality and work process through critical reflection. The objective of this descriptive study with qualitative approach was to analyze the on-the-job learning process of the Family Health Strategy in the Complexo do Alemão, Rio de Janeiro-RJ, Brazil based on the health technologies. Systematic observation and semistructured interviews were carried out with physicians, nurses, and orthodontists between December of 2007 and February of 2008 . The data compiled was then submitted to content analysis. The results show that these professionals express knowledge acquired through everyday work experiences and permanent education activities, thus constituting a pedagogical process of teaching-learning among multidisciplinary teams, but little-used in education actions by Brazilian Federal Health Care System management.
\end{abstract}

DESCRIPTORS: Family health program. Health education. Learning.

\section{EL APRENDIZAJE-TRABAJO Y LAS TECNOLOGÍAS DE SALUD EN LA ESTRATEGIA DE SALUD FAMILIAR}

\begin{abstract}
RESUMEN: La formación y capacitación de los trabajadores para el Sistema Único de Salud son cuestiones fundamentales para la Estrategia de Salud Familiar. La Educación Permanente surge como una propuesta basada en el concepto de aprendizaje-trabajo, que a través de la reflexión crítica, despierta el profesional sobre su realidad y proceso de trabajo. Es un estudio descriptivo, con abordaje cualitativo, basado en las tecnologías de la salud, cuyo objetivo fue examinar el proceso de aprendizaje-trabajo en la Estrategia de Salud Familiar, en el Complexo do Alemão, Rio de Janeiro-RJ. Se realizó observación sistemática y entrevistas semiestructuradas con médicos, enfermeras y dentistas, entre diciembre de 2007 y febrero de 2008, utilizando para el examen de los datos el método de análisis de contenido. Los resultados muestran que los profesionales expresan los conocimientos aprehendidos en la experiencia cotidiana del trabajo y en las actividades de educación permanente, generando un proceso educativo de enseñanza-aprendizaje de los equipos multidisciplinarios, pero poco utilizado en acciones de educación por los gestores del Sistema Único de Salud.
\end{abstract}

DESCRIPTORES: Programa de salud familiar. Educación para la salud. Aprendizaje. 


\section{INTRODUÇÃO}

A Estratégia Saúde da Família (ESF), que representa atenção à saúde focada na família e na comunidade, pressupõe a adequação às diferentes realidades locais, baseada na relação do trabalhador-usuário através do vínculo de compromisso e co-responsabilização. ${ }^{1}$ Implica em mudanças significativas na relação entre os trabalhadores de saúde e a população usuária, na estruturação dos serviços e no perfil de assistência à saúde, oferecido à população.

Os desafios para a conquista da autonomia e responsabilização dos profissionais de saúde para com os usuários e a efetivação das diretrizes e princípios do Sistema Único de Saúde (SUS) são sustentados pela concepção de aprendizagemtrabalho. É por meio desta que o profissional desperta a reflexão crítica sobre sua realidade e problematiza o processo de trabalho em sua organização. Esta aprendizagem considera o diálogo com os conhecimentos e as experiências prévias para incorporação de novos saberes, resultado do aprender significativamente. $^{2}$

Coerente com a temática apresentada, o objeto deste estudo é o processo de trabalho dos profissionais de enfermagem, medicina e odontologia das equipes multiprofissionais de um módulo da ESF, no Complexo do Alemão, Município do Rio de Janeiro-RJ.

O SUS encontra, ainda hoje, múltiplos obstáculos para sua efetividade. Encontramos "nós" na macropolítica em saúde, que vão desde a falta de recursos financeiros passando pela deficiente intersetorialidade, até a carência de profissionais aptos a trabalhar com a concepção de saúde ampliada. Estas dificuldades implicam em baixa virtude de produzir efeitos nas ações e serviços públicos de saúde; no descrédito da população usuária que não percebe melhorias em sua qualidade de vida e na insatisfação e frustração dos trabalhadores de saúde.

Esse cenário tem constituído um desafio para os sujeitos envolvidos diretamente no processo de trabalho em saúde, apontando a necessidade de intervenção no modo de trabalhar e nas relações trabalhador-usuário estabelecidas na micropolítica do processo de trabalho em saúde: "[...] é no cotidiano dos nossos trabalhos e no processo coletivo de gestão dos nossos serviços, a fim de resolver os problemas que identificamos no dia-a-dia, que iremos caminhar nessa direção, construindo um outro proceder em saúde que se oriente pela constituição de um vínculo efetivo entre o usuário e os trabalhadores do setor, na busca de uma resolutividade que se oriente por ganhos de autonomia dos usuários perante os seus modos de andar na vida" . 3:126

Sendo assim, a capacitação de recursos humanos para o SUS é questão essencial para a política de saúde nos seus níveis de macro e micro gestão. Além disso, a ESF incorporou novos elementos para a reorientação do processo de trabalho em saúde, que clamam por profissionais capazes de operar as inovadoras propostas. Destacam-se tecnologias de saúde como o acolhimento, a produção do vínculo, a autonomização e a gestão compartilhada de processos de trabalho como orientadoras das práticas em serviços de saúde. ${ }^{4}$ Estes elementos compõem uma porção subjetiva do processo de trabalho, que está intrinsecamente ligado ao produto das relações dialógicas entre o sujeito trabalhador e o sujeito usuário. Tal produto é fruto de um encontro entre vozes e escutas de ambos os sujeitos, caracterizando novas relações definidas como intersecção partilhada. ${ }^{3}$

Conceituando estes elementos nos defrontamos com as tecnologias leves que expressam relações dependentes necessariamente do contato direto entre sujeitos. A noção de acolhimento pode ser entendida como acesso universal, como uma relação entre pessoas valorizando a fala e a escuta, na perspectiva do desenvolvimento da autonomia, como uma forma de responsabilização e como forma de reorganização dos processos de trabalho, valorizando os ruídos do cotidiano. ${ }^{4} Q$ Quando se faz uso de tecnologias leve-duras, que são os conhecimentos técnicos, o profissional de saúde associa os saberes estruturantes do cuidado em saúde à subjetividade das relações interpessoais, ou seja, o componente leve. O acolhimento, bem como os demais elementos estão ligados a outro conceito denominado trabalho vivo em ato, ${ }^{3}$ que é aquele que acontece no momento das relações entre os sujeitos, ou seja, humano. O vínculo surge como um elemento que depende "[...] da produção do compromisso cotidiano do trabalhador de saúde diante do cuidado" 3:126 Nesse sentido, o trabalho vivo em ato traduz a articulação dos saberes do trabalhador com os saberes do usuário, constituindo assim, uma mútua cumplicidade, o que vem a ser denominado vínculo.

Todos os elementos citados anteriormente compõem o cenário da micropolítica do processo de trabalho. Nos serviços de saúde se encontram muitos profissionais com formação não contemporânea ao SUS e a ESF. Esses trabalhadores tiveram 
que passar por processos de mudanças paradigmáticas para atuarem no SUS e, sem dúvida, a Educação Permanente é um potente instrumento para enfrentar esses descompassos. O desenvolvimento consistente de ações de educação permanente contribuiu para a superação de problemas a partir do cotidiano do exercício profissional, centrando no modo de trabalho e na relação trabalhador-usuário na busca por competências favoráveis à qualidade do atendimento a população.

O objetivo da Educação Permanente “[...] deve ser a transformação das práticas profissionais e da própria organização do trabalho, tomando como referência as necessidades de saúde das pessoas e das populações, da gestão setorial e do controle social em saúde". 5:49 Todavia, para que exista um processo dialético, ou seja, criado e recriado na reflexão crítica da prática/trabalho entre os diversos saberes, trabalhadores e comunidade, científico e popular, faz-se necessário que a proposta de Educação Permanente oriente as transformações do processo de trabalho incluindo as necessidades de aprendizagem da equipe multiprofissional baseada nos valores da comunidade, seus conhecimentos, hábitos e atitudes. Os processos de qualificação dos profissionais de saúde devem servir para ocupar espaços, preencher vazios, a partir da observação dos problemas do dia-dia do trabalho, garantindo a qualidade e a satisfação da atenção prestada ao usuário. ${ }^{2}$

A Lei $N^{0} 8.080 / 90$ preconiza a criação de comissões permanentes de integração entre os serviços de saúde e as instituições de ensino. ${ }^{6}$ Como resultado do esforço em articular esses setores é instituída, em 2004, a Política Nacional de Educação Permanente por meio da Portaria No $198 /$ GM/MS, ${ }^{7}$ posteriormente, alterada pela portaria GM/MS No 1.996 , de 2007. ${ }^{8}$

Esta investigação buscou responder a seguinte questão norteadora: como o processo de aprendizagem-trabalho influencia na re-elaboração das práticas de equipes multiprofissionais da ESF na perspectiva da relação trabalhador-usuário? Diante do exposto, o objetivo que emerge neste estudo é analisar o processo de aprendizagem-trabalho de cinco equipes multiprofissionais da ESF no Complexo do Alemão, com base nas tecnologias de saúde.

\section{MÉTODO}

Estudo descritivo, com abordagem qualitativa. O cenário foi um módulo de Saúde da Família situado no Complexo do Alemão, Rio de Janeiro-
RJ, sob a Coordenação de Área Programática 3.1. Os sujeitos do estudo foram 13 profissionais de nível superior - enfermeiras(os), médicos(as) e odontólogos(as). Todos aceitaram participar do estudo e assinaram o Termo de Consentimento Livre e Esclarecido. Durante a etapa de entrevista, por diversos motivos, entre os quais, período de férias, demissão e desistência na participação do estudo, cinco sujeitos foram descartados da pesquisa, tendo como material final de análise a fala e a observação do processo de trabalho de oito profissionais de saúde.

Este estudo obteve aprovação no Comitê de Ética em Pesquisa da UNIRIO, em 27.08.2007, como requisito para submissão à solicitação de bolsas Iniciação cientifica e no CEP-SMS/RJ em 17.12.2007, Parecer No 254A-2007, exigência para toda atividade de pesquisa que envolve seres humanos em unidades de saúde da Secretaria Municipal de Saúde do Rio de Janeiro.

O trabalho de campo envolveu dois momentos: o primeiro, de observação e registro das práticas profissionais e o segundo, com entrevistas visand o a compreender elementos do processo de aprendizagem-trabalho da equipe da ESF a partir da fala dos sujeitos do estudo.

No primeiro momento de investigação, observou-se ativa e diretamente os sujeitos e o local do fenômeno. A técnica da observação para a coleta de dados exige "[...] conseguir as informações através da visão, audição e análise dos fatos que se deseja estudar" .9:46 Para tal, utilizamos um instrumento de coleta de dados, previamente elaborado. Essa técnica é chamada de observação sistemática - ou estruturada, planejada ou controlada, faz-se uso de instrumentos para a coleta dos dados ou fenômenos analisados. ${ }^{9}$

No segundo momento, foi aplicada a entrevista semi-estruturada. O roteiro da entrevista foi previamente testado e os ajustes foram feitos. As citações das entrevistas e das observações que indicam cada profissional serão aqui apresentadas por ordem cronológica de realização das observações, seguindo o seguinte padrão: E1, E2, E3 ou O1, O2, $\mathrm{O} 3$ e assim por diante.

Concomitante ao trabalho de campo houve a revisão da literatura por meio e busca bibliográfica, seleção de artigos, estudos, dissertações e teses sobre o tema/objeto de estudo e leitura para construção de texto que fundamenta a análise. $\mathrm{O}$ método de análise do material obtido da observação não-participante e das entrevistas foi a análise de conteúdo, com a técnica de análise temática. 
A noção de tema compreende um feixe de relações e pode ser representado através de uma palavra, uma frase ou um resumo. "O tema é a unidade de significação que se liberta naturalmente de um texto analisado segundo critérios relativos à teoria que serve de guia de leitura". 10:208 A transformação dos dados brutos em núcleos de sentidos (as categorias) chama-se análise temática, ou seja, "qualitativamente a presença de determinados temas denota os valores de referência e os modelos de comportamento presentes no discurso". 10:209

As etapas da análise temática foram desenvolvidas com o apoio do software Atlas.ti 5.0, uma ferramenta tecnológica para análise de dados qualitativos. ${ }^{11}$ As etapas deste estudo estão divididas em: a) pré-análise: consiste na leitura exaustiva do material estudado; o resgate das hipóteses iniciais e emergentes e as teorias que têm aderência ao estudo; organização do material. b) exploração do material: transformação dos dados brutos, visando o alcance da compreensão do texto. Esta etapa constitui primeiramente no recorte do texto em unidades de registro e, posteriormente, na realização da classificação e agregação dos dados. c) tratamento dos resultados obtidos e interpretação: a partir da análise dos dados são feitas inferências realizando interpretações articuladas com o arcabouço teórico. ${ }^{10}$

Com o uso do software Atlas.tie de suas ferramentas é possível codificar as falas segundo as categorias de análise. ${ }^{11}$ Foi feito agrupamento de todos os documentos primários em um único projeto denominado Unidade Hermenêutica (UH), no qual é possível explorar e interpretar as informações. A base teórica permitiu a definição de categorias (codes), as quais, posteriormente, foram utilizadas na análise de conteúdo. No decorrer do estudo apareceram elementos novos que suscitaram hipóteses emergentes e assim, novas categorias.

Na leitura das entrevistas e das observações, cada documento foi dividido em citações (quotations), que correspondem a trechos relevantes para o estudo. Depois de selecionada pelo pesquisador, a citação foi então conectada a uma ou mais categorias relacionadas. Feitas as interpretações, foi necessário agrupar em famílias de categorias. Categorias mais fracas ou que tiveram pouca ênfase no estudo foram re-agrupadas ou absorvidas pelos grupos familiares, conforme identificação umas com as outras. As famílias ou conjunto de categorias originadas foram: ESF, processo de trabalho em saúde, tecnologias de saúde e aprendizagem-trabalho. As famílias com relações adjacentes revelaram asso- ciações que traduzimos em dois temas: Processo de Trabalho em Saúde na ESF e A Educação Permanente, o processo de Aprendizagem-trabalho e a influência das Tecnologias Leves.

\section{RESULTADOS E DISCUSSÃO}

\section{Processo de trabalho em saúde na Estratégia da Saúde da Família}

Para compreender a natureza do processo de trabalho em saúde faz-se necessário resgatar alguns de seus conceitos e de sua organização, com ênfase na produção propriamente dita dos serviços de saúde. A definição de tecnologia que se utiliza neste estudo é a imagem dos saberes que permitem, em um processo de trabalho específico, operar sobre recursos na realização de finalidades perseguidas e postas para este processo produtivo, ${ }^{3}$ não sendo confundida como instrumento/ equipamento tecnológico.

O processo de trabalho em saúde pode ser entendido quando um trabalhador de saúde encontra-se com um usuário e estabelece-se entre eles um espaço intercessor. ${ }^{3}$ Com o uso de suas ferramentas (conhecimentos, equipamentos, tecnologias de um modo geral), o trabalhador atua no momento do ato em saúde junto ao usuário tornando-o parte de sua intervenção (como sua matéria-prima), considerando sempre seus conhecimentos e representações.

Ao iniciarem a consulta, falam sobre a situação da dengue. O médico pergunta como está a situação da epidemia na comunidade e dá dicas de como evitar a proliferação do mosquito em casa. Pergunta se o casal modificou seus hábitos alimentares como orientado durante a consulta anterior, e a mulher confirma a adesão ao novo modelo alimentar. Os pacientes levantam dúvidas sobre os tipos de alimentos que poderiam ser consumidos e são esclarecidos pelo médico que enumera a partir dos alimentos preferenciais (O7).

O que se produz no encontro desses sujeitos chamamos de relação ou intersecção partilhada. Neste encontro, a subjetividade e as singularidades tanto do trabalhador como do usuário são expressas e se configuram na existência de momentos únicos, que demandam relações e intervenções específicas às necessidades expressas pelo usuário. ${ }^{3}$ Espera-se, desse modo, ampliar a dimensão cuidadora e garantir o vínculo e a co-responsabilização entre trabalhador e usuários.

A mãe entra no consultório com suas duas filhas. É a primeira vez que a mãe é atendida na ESF, por isso 
a enfermeira se apresenta formalmente. Diz que seria importante acompanhar a família e que gostaria de agendar consulta para os demais membros da família. [...] Durante a anamnese, descobre situações importantes sobre a família, como as condições de estudo, hipertensão, fumo e problemas respiratórios $(\mathrm{O} 4)$.

Quando o usuário é colocado como elemento externo ao processo, como um objeto a ser moldado pelo saber irrefutável do trabalhador, esta relação constitui-se em uma intersecção objetal ou relação objetal. ${ }^{3}$

Houve muita evolução tecnológica, instrumentos sofisticados, então a medicina perdeu um pouco da parte humana. As pessoas agora se vêem mais voltadas para coisas supérfluas, [...] mais voltadas para o diagnóstico, nas coisas eletrônicas, elétrica, computadorizada, [...] isso aí afastam (um) pouco (o) profissional do indivíduo (E6).

Na Atenção Básica cabe às equipes de saúde, com a confluência de seus múltiplos saberes e práticas, o esforço para identificar e atender às necessidades de saúde.

A gente identifica [as necessidades de saúde] a partir da demanda dos próprios agentes comunitários $e$ as discussões de reunião de equipe. [...] Eu sinto a necessidade e faço com os meus agentes encontros quase que diários (E3).

Dentre as necessidades de saúde, uma que se destaca é o acesso e o poder para consumir tecnologias de saúde capazes de melhorar e prolongar a vida. Pode-se dizer que essas tecnologias adquirem certo valor de uso, "sempre definido a partir da necessidade de saúde de cada pessoa, em cada momento singular que vive", ${ }^{12: 115}$ ou seja, são histórica e socialmente determinadas.

O que as pessoas querem, o que esperam, não é, muita das vezes o que gente quer. A gente tem que resolver o problema do esgoto, mas nem sempre a necessidade daquela comunidade naquele momento é o esgoto (E1).

Destacamos as tecnologias leves representadas neste estudo pelo acolhimento, produção de vínculo, responsabilização e autonomização, por visualizar a qualidade das relações entre as equipes da ESF, usuários e comunidade. A noção de acolhimento pode ser entendida como acesso universal, uma relação entre pessoas valorizando a fala e a escuta. Não deve se restringir apenas ao setor de recepção, como uma forma convencional de triagem dos usuários.

Eu canso de falar para eles, a gente sempre conversa nas reuniões, eu sempre falo: quando você aborda o seu paciente você vê se ele está feliz? Se ele está alegre, se ele está bem-humorado? Porque de repente, isso dai esconde algum problema que ele tenha (E7).

$\mathrm{O}$ vínculo representa a responsabilização das equipes multiprofissionais pelo problema do indivíduo ou da coletividade, constituindo referências entre sujeitos.

Ao final da consulta a mãe e a avó elogiam a enfermeira e a equipe, falando sobre a boa relação que a família construiu com os profissionais durante o tempo de funcionamento do módulo do PSF (O3).

Porque aqui além de ver o indivíduo aqui dentro no meu consultório, eu sei o que se passa na casa dele. [...] E ele se sente à vontade porque ele sabe que eu sei, então a nossa consulta excede muita coisa [...] é um espaço que para mim foi de grande crescimento (E3).

A responsabilização expressa a capacidade do sistema de saúde e seus trabalhadores em assumir a responsabilidade pelos problemas de saúde de uma população ou de um indivíduo. O que provocaria, por parte do indivíduo, o abandono de uma atitude passiva com relação à sua própria saúde.

A equipe chamava os moradores para fora de suas casas para observarem as situações encontradas, onde seria possivel emergir criadouros de mosquitos. Tentavam resolver os problemas juntos, levantando propostas (O8).

Destaca-se no tema I o descompasso entre a formação dos profissionais de saúde que atuam na ESF, com ênfase nas tecnologias leve-duras e a necessidade de aprender a utilizar as tecnologias leves para estabelecer relações entre sujeitos.

\section{A educação permanente, o processo de aprendizagem-trabalho e a influência das tecnologias leves}

Ao considerar o curto período histórico da ESF como política para a atenção básica em saúde e o tempo de formação dos profissionais que hoje se encontram nos módulos, poder-se-ia esperar carência de profissionais com o perfil adequado ao novo campo de conhecimento instituído.

[...] nunca trabalhei na Estratégia, minha formação era basicamente hospitalocêntrica. [...] Eu nunca tinha visto o SUS na essência e quanto mais o PSF que se era novo, de um modo geral pra todos, pra mim era mais novo ainda porque a minha formação era outra (E4).

Para tanto, desde a criação do SUS, reorganizar as práticas de atenção à saúde significa instituir novas políticas de formação e processo contínuo de 
aprendizado de trabalhadores de saúde. A educação permanente em saúde permite a transformação do processo de trabalho, corrigir descompassos e atender as necessidades do SUS, a partir da "[...] reflexão sobre o que está acontecendo no serviço e sobre o que precisa ser transformado". 13:06

Educação permanente. [...] Na verdade seria você estar sempre, não se fala mais em reciclando, mas é educação em serviço. Você reflete sobre a sua prática, diante de alguns marcos teóricos (E3).

Além do curso Introdutório, são oferecidas, ainda, com certa regularidade, capacitações pela Secretaria Municipal de Saúde do Rio de Janeiro que servem como educação continuada aos profissionais. São vistos como possibilidade de melhorar sua competência sobre determinado assunto ou a necessidade de recuperar conhecimentos e habilidades esquecidas. Entre as mais lembradas e citadas pelos profissionais estão os programas considerados, pelo Ministério da Saúde e pelos gestores locais, prioritários para a ESF.

Fiz o Atenção Integral às Doenças Prevalentes na Infância (AIDPI), a Estratégia DOTS (Directly Observed Therapy Short-Course), capacitação em saúde da mulher com a médica que é ginecologista, já fiz planejamento familiar, pré-natal, foram muitas (E1).

Eu fiz DOTS, fiz AIDPI, fiz algumas que eram obrigatórias, questão de imunização, [...] tem as capacitações do GAT (Grupo de Apoio Técnico), que é a oficina permanente, cada mês tem um tema (E3).

Durante a minha estada aqui eu fiz o curso de avaliadores da Iniciativa Unidade Básica Amiga da Amamentação, fiz o curso de hanseniase, o DOTS [...]. E um de idosos (E4).

Nas situações de qualificação, os trabalhadores reconhecem a necessidade de práticas pedagógicas problematizadoras, que vão além do como devia ser.

Tinham capacitações que eram pura transmissão, então essas realmente não me acrescentavam nada. Agora, algumas que eu fui principalmente lá no GAT, eles problematizavam a discussão. Então ficava uma coisa mais participativa com a gente (E6).

Os profissionais relatam, ainda, que em seus serviços a realidade, por vezes, é outra e impossibilita a aplicação de diversos conhecimentos adquiridos, seja pelas limitações no processo de trabalho ou nas relações entre a equipe de saúde e a população.

Na prática eu tive uma decepção porque o introdutório te mostra um trabalho que nem sempre a gente consegue por na prática, entendeu? (E6).
No dia-a-dia a realidade se impõe com outras circunstâncias. A discussão no curso do introdutório serviu para muito pouco. Devido à realidade da própria comunidade (E5).

É importante que tais cursos compreendam que "[...] experiência cotidiana do trabalho e as situações reais vivenciadas [...] representam uma aprendizagem permanente ${ }^{\prime \prime}{ }_{13: 5}$ ou seja, reconhecer a existência da aprendizagem-trabalho.

[...] na verdade se eu estou em relação com alguém ou com uma coisa que envolve o meu trabalho, eu to numa dialética e essa dialética para mim é criadora de novidades (E8).

No processo de educação permanente, no qual os indivíduos devem estar abertos a aprender a aprender, as metodologias pedagógicas devem se basear na aprendizagem significativa. Diferente da aprendizagem mecânica que preza pelo acúmulo de conteúdos, na aprendizagem significativa há diálogo com as experiências prévias que cada um tem. A aprendizagem significativa se dá "[...] tanto por meio da descoberta como por meio da repetição", 14:39 ou seja, aprender uma novidade que faça sentido para o trabalhador também pode se dar no processo de trabalho. O conhecimento quando adquirido de maneira significativa "[...] é retido e lembrado por mais tempo e aumenta a capacidade de aprender outros conteúdos de uma maneira mais fácil, mesmo se a informação original for esquecida". ${ }^{14: 39}$

Foi uma elucidação da teoria, mas ela foi bem enfática na prática do trabalho. [...] Então, eu acho que essas capacitações, a maioria delas, enfatizaram o trabalho, a aprendizagem no trabalho dessa forma prática que é o importante, que a gente faz no dia-adia e não enfatizaram tanto a teoria, os conceitos mais maçantes (E7).

Repensar a relação trabalhador-usuário, passa por re-elaborar a dimensão objetiva e técnica das práticas institucionais nos processos de educação permanente. Por vezes, se traduzem na normatização das tarefas, que reforçam a fragmentação do cuidado e a divisão social do trabalho. O Agente Comunitário de Saúde (ACS) é treinado e cobrado para agendar consultas; a enfermeira para entregar preventivo, organizar a farmácia, realizar triagem dos pacientes; o médico para consulta médica.

[...] você começa a ver o outro, a necessidade do outro não como alguma coisa importante. Aí você começa a olhar com o seu olhar: ah, isso não é importante. Manda a pessoa ir embora, volta outro dia! Agenda uma consulta (E1). 
Na aplicação das tecnologias leves, as equipes podem tomar consciência dos problemas e se reconhecer como sujeito na busca por melhorias na saúde da população. Nas falas dos profissionais foi observado o empenho em modificar seus processos de trabalho, com tentativa de envolver toda equipe na resolução das necessidades de saúde.

Até as capacitações, eu costumo fazer [...] reuniões semanais sobre hipertensão e diabetes, onde o ACS faz esse contato com o paciente, explicando a doença, o tratamento (E6).

Hoje mesmo eu falei para os meus agentes: nós temos 17 gestantes, somente oito estão fazendo pré-natal aqui. Aí eles falaram: que bom né? Menos trabalho para a gente. Aí eu falei: não é que bom, é porque tem alguma coisa errada. Porque elas não querem fazer o pré-natal aqui? É isto que a gente tem que saber. Não é questão do mais trabalho ou do menos trabalho. Tem que ter um motivo. Ou elas têm um plano de saúde e preferem acompanhar fora, porque não querem ser acompanhadas pelo SUS, ou porque algum de nós algum dia deixou alguma falha com elas. A gente precisa resgatar isso (E1).

A Educação Permanente concebida como política pública de qualificação para o trabalho em saúde no SUS, embasa-se no conceito de aprendizagem-trabalho. Tal conceito implica em realizar mudanças com os profissionais em atividade, a partir de suas experiências, de modo auto-reflexivo e crítico.

\section{CONSIDERAÇÕES FINAIS}

A ESF é considerada pelo Ministério da Saúde como a principal política re-orientadora do modelo de atenção à saúde no país. A implantação em comunidades da cidade do Rio de Janeiro com baixo Índice de Desenvolvimento Humano, elevados riscos sociais e ambientais, como é o caso do Complexo do Alemão, trazem grandes desafios aos gestores dos serviços de saúde. A realidade social da população estudada, marcada pela violência urbana e estrutural, influencia fortemente no processo de trabalho das equipes multiprofissionais, provoca descontinuidade da atenção à saúde e perda de vínculo na relação trabalhador-usuário.

As políticas de formação dos trabalhadores da saúde devem considerar que as realidades encontradas no SUS são complexas. Quando as equipes de saúde da ESF conseguem superar tais barreiras, competências e habilidades com base nas relações partilhadas, como as tecnologias leves de acolhimento, vínculo e responsabilização demonstraram ampliar o acesso às ações da saúde oferecidas à população e induzir a integralidade da assistência. Dessa forma, o sistema público poderá vir a se responsabilizar pelo usuário em todos os níveis de atenção. É preciso envolver os trabalhadores para que usem seus arsenais tecnológicos na busca de serviços eficientes e satisfação das necessidades da população. É necessário também reconhecer o usuário como sujeitos protagonistas, que influenciam e são parte do processo de produção do cuidado em saúde.

A aprendizagem-trabalho, amplamente citada pelos profissionais que participaram do estudo, constitui uma ferramenta para o desenvolvimento de capacitações com práticas pedagógicas que relacionem a gestão e organização dos serviços com a interdisciplinaridade das ações das equipes de saúde. É possível afirmar que os profissionais expressam, no processo de trabalho em saúde, conhecimentos apreendidos nas experiências cotidianas do trabalho e a partir de situações reais vivenciadas. Pode-se dizer que a aprendizagemtrabalho se constitui como processo pedagógico de ensino-aprendizagem no dia-a-dia das equipes multiprofissionais. Mostrou-se permanente quando junto a profissionais comprometidos com o fazer em saúde, porém, ainda incipiente como um recurso para os gestores dos serviços integrarem as ações de educação profissional.

\section{REFERÊNCIAS}

1. Silva RVB, Stelet BP, Pinheiro R, Guizardi FL. Do elo ao laço: o agente comunitário na construção da integralidade em saúde. In: Pinheiro R, Mattos RA, organizadores. Cuidado - as fronteiras da integralidade. Rio de Janeiro (RJ): Hucitec/ Abrasco; 2004. p.75-89.

2. Ministério da Saúde (BR), Secretaria de Gestão do Trabalho e da Educação na Saúde, Departamento de Gestão da Educação na Saúde. A educação permanente entra na roda. Brasília (DF): MS; 2005.

3. Merhy EE. O SUS e um de seus dilemas: mudar a gestão e a lógica do processo de trabalho em saúde (um ensaio sobre a micropolítica do trabalho vivo). In: Fleury S, organizador. Saúde e democracia: a luta do CEBES. São Paulo (SP): Lemos Editorial; 1997. p.125-41.

4. Marques GQ, Lima MADS. As tecnologias leves como orientadoras dos processos de trabalho em serviços de saúde. Rev Gaúch Enferm. 2004 Abr; 25(1):17-25.

5. Ceccim RB, Feuerwerker LCM. O quadrilátero da formação para a área da saúde: ensino, gestão, atenção e controle social. Physis: Rev Saúde Coletiva. 2004 Jan-Jun; 14(1):41-65. 
6. Brasil. Lei $\mathrm{N}^{\circ}$ 8080, de 19 de Setembro de 1990: dispõe sobre as condições para a promoção, proteção e recuperação da saúde, a organização e o funcionamento dos serviços correspondentes e dá outras providências. Diário Oficial da República Federativa do Brasil, 19 Set 1990.

7. Brasil. Portaria $\mathrm{N}^{\circ} 198 / \mathrm{GM}$, de 13 de fevereiro de 2004 Institui a Política Nacional de Educação Permanente em Saúde como estratégia do Sistema Único de Saúde para a formação e o desenvolvimento de trabalhadores para o setor e dá outras providências. Diário Oficial da República Federativa do Brasil, 13 Fev 2004.

8. Brasil. Portaria $\mathrm{N}^{\circ} 1996 / \mathrm{GM} / \mathrm{MS}$, de 20 de agosto de 2007: dispõe sobre as diretrizes para a implementação da Política Nacional de Educação Permanente em Saúde e dá outras providências. Diário Oficial da República Federativa do Brasil, 20 Ago 2007.

9. Soares LES. Pesquisa em comunicação social: um inventário das teses e dissertações defendidas no programa de Pós-Graduação da FAMECOS [dissertação]. Porto Alegre (RS): Pontifícia Universidade Católica do Rio Grande do Sul; 2004.

10. Minayo MCS. O desafio do conhecimento: pesquisa qualitativa em saúde. $7^{\text {a }}$ ed. São Paulo/Rio de Janeiro (SP/RJ): Hucitec/Abrasco; 2000.

11. Atlas.ti [programa de computador]. The Knowledge Workbench. Visual Qualitative Data Analysis. Version: Win 5.0. Berlin (DE): Scientific Software Development; 2008

12. Cecílio LCO. As necessidades de saúde como conceito estruturante na luta pela integralidade e equidade na atenção em saúde. In: Pinheiro R, Mattos R, Araújo organizadores. Os sentidos da integralidade na atenção e no cuidado à saúde. Rio de Janeiro (RJ): UERJ; 2001. p.113-26.

13. Ribeiro ECO, Motta JIJ. Educação permanente como estratégia na reorganização dos serviços de saúde. Divulg Saúde Debate. 1996 Jul; (12):39-44.

14. Pelizzari A, Kriegl ML, Baron MP, Finck NTL, Dorocinski SI. Teoria da aprendizagem significativa segundo Ausubel. Revista PEC. 2001-2002; 2(1):37-42. 